\title{
The Efficiency of Dynamic vs General Exercise for Posture Control Dealing with Low Back Pain
}

\author{
Michael Mendoza \& MinHyuk Kwon \\ California State Polytechnic University, Pomona, USA
}

\begin{abstract}
Mechanical low back pain is brought on by associated factors, such as muscular imbalances, excess muscular stress, and improper posture. Proper posture is vital for treating low back pain because of its unloading effects on the spine. Thus, the purpose of this critiqued article is to explore which is an effective and functional exercise that can be done at any time for posture.
\end{abstract}

Keywords: exercise, posture, mechanical low back pain

Article History

Received 26 September 2020

Accepted 11 October 2020

Published 31 January 2021

Available online 19 February 2021

https://doi.org/10.47544/johsk.2021.2.1.5

$\begin{array}{r}\text { Corresponding Author } \\ \text { MinHyuk Kwon } \\ \text { minhyukkwon@cpp.edu }\end{array}$
Department of Kinesiology \& Health Promotion
College of Science
California State Polytechnic University, Pomona, USA

\section{Methods}

Thirty adults (20-30 years old, 14 males and 16 females) with chronic as opposed to acute or surgery, mechanical low back pain were splitted into Dynamic Sitting Exercise (DSE) and Spinal Extension Exercise (SEE). DSE sUbject is unloading the spine using the arms while sitting in an upright position. SEE subject is laying prone in elbow position doing a press up with straight arms. Testing was conducted 3 days per week for 6 weeks. Back pain was measured by Visual Analogue Scale (VAS), lumbar mobility by Modified-Modified Schober Test (MMST), and quality of life through subject self-reporting using the (SF-36) health survey before and after the examination. Data were analyzed using paired t-test and Mann-Whitney U-test.

\section{Results}

A greater improvement has been shown in pain (VAS; $z=3.81, p<.05$ ) with DSE in comparison to SEE. Greater lumbar mobility (MMST; $z=1.99, p<0.05$ ) increase with DSE in comparison to SEE. A higher quality of life (SF-36; $z=$ 4.16, $p<0.05$ ) with DSE in comparison to SEE was reported. Overall, the DSE proved more effective (see Table 1).

\section{Discussion}

DSE works better because of its decompressing action unloading the disc in the spine without straining the lumbar muscles through excess abdominal activation compared to SEE. 6 weeks of DSE training is more efficient for adults with mechanical low back pain compared to SEE. DSE relieves more pressure off the mechanoreceptors leading

\section{Journal of Health, Sports, \& Kinesiology | ISSN 2692-9864 | www.johsk.com}


to greater reduction in pain while also increasing blood flow to the lumbar muscles.

Table 1. Mean and Standard Deviation of Pre- and post-Test Outcome Measures of Adults with Mechanical Low Back Pain in Between Groups. Adapted from Das, D., \& Venkatesan, R. (2020, p. 85).

\begin{tabular}{|c|c|c|c|c|c|}
\hline \multirow{3}{*}{$\begin{array}{l}\text { S1. } \\
\text { No }\end{array}$} & \multirow{3}{*}{ Outcome Measures } & \multicolumn{2}{|c|}{$\begin{array}{c}\text { Pre-Test } \\
(n=30)\end{array}$} & \multicolumn{2}{|c|}{$\begin{array}{l}\text { Post-Test } \\
(n=30)\end{array}$} \\
\hline & & $\begin{array}{c}\text { Dynamic Sitting } \\
\text { Exercise (DSE) } \\
(n=15)\end{array}$ & $\begin{array}{l}\text { Spinal Extension } \\
\text { Exercise (SEE) } \\
(n=15)\end{array}$ & $\begin{array}{l}\text { Dynamic Sitting } \\
\text { Exercise (DSE) } \\
\quad(n=15)\end{array}$ & $\begin{array}{l}\text { Spinal Extension } \\
\text { Exercise (SEE) } \\
\quad(n=15)\end{array}$ \\
\hline & & Mean $\pm S D$ & Mean $\pm S D$ & Mean \pm SD & Mean $\pm S D$ \\
\hline 1 & Pain (VAS) & $5.33 \pm 1.04$ & $5.47 \pm .89$ & $3.53 \pm 1.06$ & $4.67 \pm .62$ \\
\hline 2 & Lumbar Mobility (MMST) & $17.93+1.41$ & N/A & $18.73 \pm 1.43$ & N/A \\
\hline 3 & Quality of Life (SF-36) & $51.00+5.90$ & $51.76 \pm 5.65$ & $76.70 \pm 7.85$ & $62.56 \pm 4.08$ \\
\hline \multicolumn{2}{|c|}{ Between Group Comparison } & \multicolumn{2}{|c|}{$\begin{array}{ll}\text { VAS: } & z=1.81, p>.05 \\
\text { MMST: } & z=0.70, p>.05 \\
\text { SF-36: } & z=0.25, p>.05\end{array}$} & \multicolumn{2}{|c|}{$\begin{array}{ll}\text { VAS: } & z=3.81, p<.05 \\
\text { MMST: } & z=1.99, p<.05 \\
\text { SF-36: } & z=4.16, p<.05\end{array}$} \\
\hline
\end{tabular}

Note: Between group comparisons using paired t-test and Mann-Whitney U-test. N/A = Not Available.

\section{Critique}

The study demonstrates the efficiency advantage of DSE in comparison to SEE with their improvements in pain, lumbar mobility, and quality of life. Defining comparisons were made between the two methods allowing us to understand DSE's decompression effect on intervertebral disc as opposed to SEE's strain on lumbar muscles. The results can be interpreted and used by anyone with mechanical low back pain so they may implement the DSE routine into their daily life. The only limitations include self-reporting quality of life with SF-36 survey and sample size. Adding a different means of measuring quality of life and larger sample size $(100+)$ would improve experiment for a follow up study.

\section{Reference}

Das, D., \& Venkatesan, R. (2020). Dynamic sitting exercise versus spinal extension exercise on pain, lumbar mobility and quality of life in adults with mechanical low back pain. Indian Journal of Physiotherapy \& Occupational Therapy, 14(1). Doi: 10.5958/0973-5674.2020.00015.5 